\title{
Effects of truck transportation and slaughtering on the occurrence of prednisolone and its metabolites in cow urine, liver, and adrenal glands
}

Pierluigi Capra ${ }^{1 \dagger}$, Marta Leporati ${ }^{1,2+}$, Carlo Nebbia ${ }^{3}$, Stefano Gatto ${ }^{4}$, Alberto Attucci ${ }^{5}$, Gandolfo Barbarino ${ }^{6}$ and Marco Vincenti ${ }^{2,7^{*}}$ (D)

\begin{abstract}
Background: The recognition of illegal administration of synthetic corticosteroids in animal husbandry has been recently challenged by the case of prednisolone, whose occasional presence in the urine of bovines under strong stressful conditions was attributed to endogenous biosynthesis, not to exogenous administration. The study of the natural stress sources possibly inducing endogenous prednisolone production represents a stimulating investigation subject. The biochemical effects of transportation and slaughtering were verified in untreated cows by studying the possible occurrence of prednisolone and its metabolites in urine, liver and adrenal glands, and the cortisol/cortisone quantification.

Results: Cortisol, cortisone, prednisolone and its metabolites were measured in urine, collected at farm under natural micturition and then at the slaughterhouse. The study was performed on 15 untreated cows reared in different farms at the end of their productive cycle. 2-3 days after the first urine collection, the animals were transported by trucks to the abattoir, slaughtered, and subjected to a second urine sampling from the bladder. Specimens of liver and adrenal gland were also collected and analysed by means of a liquid chromatographytandem mass spectrometry (LC-MS/MS) validated method. The stressful conditions of transportation and slaughtering proved to increase considerably the urinary levels of cortisol and cortisone as compared to those collected at farm. Prednisolone was detected in the urine collected at the slaughterhouse of two cows only, at a concentration level $\left(\approx 0.6 \mu \mathrm{g} \mathrm{L}^{-1}\right)$ largely below the official cut off $\left(5.0 \mu \mathrm{g} \mathrm{L}^{-1}\right)$ established to avoid false noncompliances. These two animals exhibited the highest urinary cortisol levels of the series. Prednisolone and prednisone were also detected in the adrenal glands of a different cow. Prednisolone metabolites were not detected in any urine, liver, and adrenal gland sample.

(Continued on next page)
\end{abstract}

\footnotetext{
* Correspondence: marco.vincenti@unito.it

Part of the results of this study have been presented at the 2012 EAVPT Congress, Noordwijkerhout, The Netherlands.

†Pierluigi Capra and Marta Leporati contributed equally to this work.

${ }^{2}$ Centro Regionale Antidoping e di Tossicologia "A. Bertinaria", Orbassano

(Torino), Italy

${ }^{7}$ Dipartimento di Chimica, Università degli Studi di Torino, Via Pietro Giuria, 7,

10125 Torino, Italy

Full list of author information is available at the end of the article
}

(c) The Author(s). 2019 Open Access This article is distributed under the terms of the Creative Commons Attribution 4.0 International License (http://creativecommons.org/licenses/by/4.0/), which permits unrestricted use, distribution, and reproduction in any medium, provided you give appropriate credit to the original author(s) and the source, provide a link to the Creative Commons license, and indicate if changes were made. The Creative Commons Public Domain Dedication waiver (http://creativecommons.org/publicdomain/zero/1.0/) applies to the data made available in this article, unless otherwise stated. 
(Continued from previous page)

Conclusion: Within the constraints of the condition adopted, this study confirms the sporadic presence of prednisolone traces (2 samples out of 15) and the consistently increased concentration of cortisone and cortisol in the urines collected from cows subjected to truck transportation and subsequent slaughtering. No prednisolone metabolites were detected in any liver and adrenal gland samples, nor in urine specimens, unlike what was previously reported for cows artificially stressed by pharmacological treatment.

Keywords: Glucocorticoids, Prednisolone, Stress, Slaughtering, Endogenous biosynthesis, Urine, Liver, Adrenal glands, 20ß-dehydroprednisolone

\section{Background}

A wide range of steroidal molecules have been synthesized to replicate (with enhancement in efficiency and duration) the anti-inflammatory properties of corticosteroids. Among the synthetic "corticosteroid-like" molecules, prednisolone is the one with the chemical structure most similar to the natural adrenal steroids. Unlike betamethasone, dexamethasone and several other synthetic molecules, prednisolone does not contain any halogen atom and differs from cortisol uniquely for the presence of a second double bound on the A ring (Fig. 1).

Prednisolone and the other synthetic corticosteroids can be used in veterinary therapy under strict medical control to treat musculoskeletal and skin diseases, allergic reactions and shock, and other pathologies [1, 2]. These drugs are also misused to conceal animal illness or as growth-promoters, in which case they are administered at sub-therapeutic doses. Their illegal use is monitored in the EU area through National Residue Control Plans, established according to the 96/23 EC directive.

In the last years, several research groups have independently obtained experimental evidence consistent with the possibility of endogenous/natural biosynthesis of prednisolone, both in vitro [3] and in live animals $[4,5]$. Based on these evidences, the Italian Ministry of Health [6] issued a technical note establishing a precautionary threshold concentration of $5 \mu \mathrm{g} \mathrm{L}{ }^{-1}$ for prednisolone in bovine urine. This threshold was subsequently used as a legal cut-off to assess its unequivocal exogenous origin. An identical threshold was proposed later by the researchers of the E.U. Reference Laboratory [3].

In the frame of the project "Investigation on prednisolone and its metabolites in meat and milk producing bovines, assessment of endogenous biotransformation through "in vivo" and "in vitro" experiments" supported by "Regione<smiles>C[C@H]1C[C@H]2C3(F)CCC4=CC(=O)C=C[C@]4(C)[C@H]3[C@@H](O)C[C@]2(C)[C@]1(O)C(=O)CO</smiles>

Dexamethasone<smiles>CC1C[C@H]2[C@@H]3CCC4=CC(=O)C=C[C@]4(C)[C@H]3[C@@H](O)C[C@]2(C)[C@]1(O)C(=O)CO</smiles>

Betamethasone

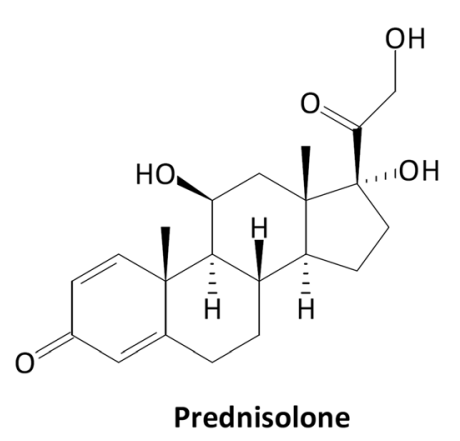

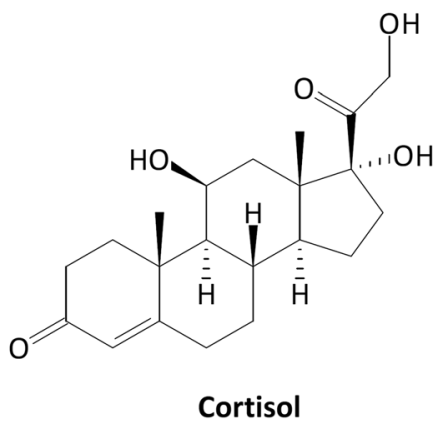

Fig. 1 Molecular structures of the most commonly used synthetic corticosteroids, dexamethasone, betamethasone, and prednisolone, highlighting the similarity between the latter and cortisol 
Piemonte-Direzione Sanità - Prevenzione Veterinaria”, a study on 131 non treated cows was first carried out throughout the years $2011 / 2012$ in order to evaluate the possible natural presence of prednisolone in their urine specimen. The presence of prednisolone at trace concentration levels (i.e., $0.1-0.3 \mu \mathrm{g} \mathrm{L}^{-1}$ ) was found in 7 animals only [7]. It is worth noting that all "positive" animals were reared in loose housing systems, thereby experiencing significant stress from the restraining and sample collection procedures, as was reflected also in an increased urinary cortisol concentration with respect to the animals usually kept tethered. In the frame of the project mentioned above, a characterization of the urinary excretion profile of prednisolone was also performed in both healthy finishing bulls and cows after the intramuscular (i.m.) administration of a therapeutic schedule [8]. Among the results of this kinetic study, it should be mentioned that very low urinary cortisol and cortisone levels were recorded at any checked time-point, along with a consistent occurrence of $20 \beta$-dihydroprednisolone and, more sporadically, other reduced or oxidized metabolites of prednisolone and prednisone.

Endogenous prednisolone was found in the urines and adrenal glands [9] of dairy cows subjected to the distinctive state of stress consequent to their transport and slaughter. More recently [10], the plasma pharmacokinetic and urinary excretion profiles of relevant glucocorticoids were investigated in cattle subjected to either exogenous prednisolone treatment or the administration of synthetic ACTH analogue tetracosactide hexaacetate to induce a stress allegedly leading to endogenous prednisolone formation. The results of this study point to the determination of the urinary prednisolone/cortisol ratio as an expedient strategy to discriminate between endogenous and exogenous prednisolone.

The present work was aimed at the evaluation of the possible occurrence of prednisolone in urine, together with the levels of cortisol and cortisone, arising from the severe stressful conditions of transport and slaughtering operation. A second objective was to assess the possible presence of prednisolone metabolites $(20 \alpha$-dihydroprednisolone, $20 \beta$-dihydroprednisolone, $6 \beta$-hydroxypredniso lone, $20 \beta$-dihydroprednisone) which have been so far associated with either therapeutic or illicit administration of the drug. The last unprecedented goal was to target the same prednisolone precursors and metabolites in liver and adrenal glands as possible organs of prednisolone biosynthesis.

\section{Results}

\section{Adrenal gland method validation} Specificity

The SRM chromatographic profiles obtained from 10 adrenal glands samples did not reveal the presence of any significant signal $(\mathrm{S} / N<3)$ at the relative retention time typical of the studied compounds and the internal standards, with the exception of cortisol and cortisone.

\section{Linearity}

The calibration curves obtained for all the analytes showed good fit and linearity over the entire range of interest (Table 1), with the exception of cortisol and cortisone. For these analytes the dynamic linear range proved narrower than that initially planned $(0.5-2.5 \mu \mathrm{g}$ $\mathrm{L}^{-1}$ and $0.5-5.0 \mu \mathrm{g} \mathrm{L}^{-1}$, respectively). The most likely explanation for the calibration curve deflection is an incomplete ionization that may occur at the highest concentrations. In practice, the real samples with cortisol or cortisone concentration exceeding the linear range had to be properly diluted in order to fall back into it.

\section{Precision and trueness}

Intraday data on precision and accuracy are reported in Table 1 . The results show satisfactory intra-day repeatability, as the percent variation coefficient (CV\%) was lower than $15 \%$ for all the spiked analytes at low, intermediate, and high concentration levels. Intraday results also exhibited optimal trueness, as the percent bias fell within few percent units in almost all cases, with maximum experimental errors of -13 and $+10 \%$.

\section{Real samples results}

All the data collected for real samples are reported in Table 2. In urine samples collected at farm, cortisol and cortisone concentrations ranged from non-detectable to $3.5 \mu \mathrm{g} \mathrm{L}^{-1}$ with the only exception of animal 13 whose sample contained $24 \mu \mathrm{g} \mathrm{L}^{-1}$ of cortisone and $52 \mu \mathrm{g} \mathrm{L}^{-1}$ of cortisol. Particularly laborious sampling operations were recorded at farm for this animal that might explain the unusually high levels for cortisol and cortisone detected in this specific sample. None of the specimens collected at farm contained measurable amounts of prednisone or prednisolone. Truck transportation and slaughtering indeed induced a sharp increase in both urinary cortisol (range $1.1 \div 145 \mu \mathrm{g} \mathrm{L}^{-1}$, median $21 \mu \mathrm{g} \mathrm{L}^{-1}$ ) and cortisone (range from non-detectable to $53 \mu \mathrm{g} \mathrm{L}^{-1}$, median $12 \mu \mathrm{g} \mathrm{\textrm {L } ^ { - }}$ $\left.{ }^{1}\right)$. In two samples (animals 2 and 15), that displayed the highest concentrations of both cortisol and cortisone, the presence of prednisolone was also detected at concentrations of 0.57 and $0.60 \mu \mathrm{g} \mathrm{L} \mathrm{L}^{-1}$, respectively.

One liver sample (animal 11) was found to contain measurable amounts of cortisol $\left(0.88 \mu \mathrm{g} \mathrm{Kg} \mathrm{Kg}^{-1}\right)$. The other specimens were negative to all the measured analytes.

Adrenal specimens exhibited uneven levels of cortisone and cortisol; in one animal (\#12), prednisone and prednisolone (Fig. 2) were detected at $3.4 \mu \mathrm{g} \mathrm{Kg}^{-1}$ and 
Table 1 Validation results of the analytical method developed for adrenal glands. Intraday precision and accuracy were calculated at three concentration levels (low, intermediate, high)

\begin{tabular}{|c|c|c|c|c|c|c|c|c|c|c|}
\hline \multirow[t]{2}{*}{ Analyte } & \multirow{2}{*}{$\begin{array}{c}\text { Instrumental } \\
\text { linearity range } \\
\left(\mu g L^{-1}\right)\end{array}$} & \multirow[t]{2}{*}{$R^{2}$} & \multicolumn{4}{|c|}{ Intraday precision (CV\%) } & \multicolumn{4}{|c|}{ Accuracy (bias \%) } \\
\hline & & & $\begin{array}{c}0.5 \\
\mu \mathrm{g} \mathrm{Kg} \\
\end{array}$ & $\begin{array}{c}2.0 \\
\mu \mathrm{g} \mathrm{Kg} \\
\end{array}$ & $\begin{array}{c}10.0 \\
\mu \mathrm{Kg}^{-1}\end{array}$ & $\begin{array}{c}20.0 \\
\mu \mathrm{g} \mathrm{Kg}\end{array}$ & $\begin{array}{c}0.5 \\
\mu \mathrm{Kg}^{-1}\end{array}$ & $\begin{array}{c}2.0 \\
\mu \mathrm{Kg}^{-1}\end{array}$ & $\begin{array}{c}10.0 \\
\mu \mathrm{g} \mathrm{Kg} \\
\end{array}$ & $\begin{array}{c}20.0 \\
\mu \mathrm{gg}^{-1} \\
\end{array}$ \\
\hline 6ß-hydroxyprednisolone & $0.10-1.0$ & 0.9953 & - & 6 & 8 & 8 & - & +4 & 0 & -7 \\
\hline 20a-dihydroprednisolone & $0.10-1.0$ & 0.9906 & - & 9 & 5 & 12 & - & -13 & -5 & +5 \\
\hline 20ß-dihydroprednisolone & $0.10-1.0$ & 0.9919 & - & 11 & 10 & 12 & - & +4 & +1 & -1 \\
\hline 20ß-dihydroprednisone & $0.10-1.0$ & 0.9900 & - & 8 & 9 & 7 & - & -9 & -6 & +5 \\
\hline Prednisolone & $0.025-0.50$ & 0.9988 & 6 & 8 & 7 & - & +10 & +6 & +4 & - \\
\hline Prednisone & $0.025-0.50$ & 0.9995 & 11 & 5 & 9 & - & +7 & +3 & +1 & - \\
\hline Cortisol & $0.50-2.5$ & 0.9962 & & & & & & & & \\
\hline Cortisone & $0.50-5.0$ & 0.9983 & & & & & & & & \\
\hline
\end{tabular}

Table 2 Analytical results obtained for urine and adrenal gland samples. Unavailable samples are indicated with N.A., while N.D. stays for "not detectable"

\begin{tabular}{|c|c|c|c|c|c|c|c|c|}
\hline \multicolumn{9}{|c|}{ Urine samples } \\
\hline \multirow[t]{2}{*}{ Animal } & \multicolumn{2}{|c|}{ Cortisone $\left(\mu \mathrm{g} \mathrm{L}^{-1}\right)$} & \multicolumn{2}{|c|}{ Cortisol $\left(\mu \mathrm{g} \mathrm{L}^{-1}\right)$} & \multicolumn{2}{|c|}{ Prednisone $\left(\mu \mathrm{g} \mathrm{L}^{-1}\right)$} & \multicolumn{2}{|c|}{ Prednisolone $\left(\mu \mathrm{g} \mathrm{L}^{-1}\right)$} \\
\hline & Farm & Slaughterhouse & Farm & Slaughterhouse & Farm & Slaughterhouse & Farm & Slaughterhouse \\
\hline 1 & N.D. & 16 & N.D. & 23 & N.D. & N.D. & N.D. & N.D. \\
\hline 2 & 1.5 & 49 & N.D. & 98 & N.D. & N.D. & N.D. & 0.57 \\
\hline 3 & N.A. & 6.5 & N.A. & 9.1 & N.A. & N.D. & N.A. & N.D. \\
\hline 4 & N.A. & 18 & N.A. & 45 & N.A. & N.D. & N.A. & N.D. \\
\hline 5 & N.D. & N.D. & 0.68 & 1.1 & N.D. & N.D. & N.D. & N.D. \\
\hline 6 & N.D. & 5.3 & 1.5 & 12 & N.D. & N.D. & N.D. & N.D. \\
\hline 7 & 1.1 & 1.6 & 2.1 & 2.6 & N.D. & N.D. & N.D. & N.D. \\
\hline 8 & N.D. & 3.9 & N.D. & 7.8 & N.D. & N.D. & N.D. & N.D. \\
\hline 9 & N.D. & 8.5 & N.D. & 15 & N.D. & N.D. & N.D. & N.D. \\
\hline 10 & 0.69 & 25 & 1.1 & 44 & N.D. & N.D. & N.D. & N.D. \\
\hline 11 & N.D. & 16 & N.D. & 21 & N.D. & N.D. & N.D. & N.D. \\
\hline 12 & 1.4 & 3.6 & 3.5 & 5.2 & N.D. & N.D. & N.D. & N.D. \\
\hline 13 & 24 & 12 & 52 & 31 & N.D. & N.D. & N.D. & N.D. \\
\hline 14 & 0.60 & 16 & 1.0 & 32 & N.D. & N.D. & N.D. & N.D. \\
\hline 15 & 1.6 & 53 & 2.4 & 145 & N.D. & N.D. & N.D. & 0.60 \\
\hline \multicolumn{9}{|c|}{ Adrenal glands samples } \\
\hline Animal & & ne $\left(\mu \mathrm{Kg}^{-1}\right)$ & & $\mathrm{ol}\left(\mu \mathrm{g} \mathrm{Kg}{ }^{-1}\right)$ & Pre & one $\left(\mu \mathrm{g} \mathrm{Kg}^{-1}\right)$ & Pre & lone $\left(\mu \mathrm{g} \mathrm{Kg}^{-1}\right)$ \\
\hline 1 & & 476 & & 150 & & N.D. & & N.D. \\
\hline 2 & & 682 & & 905 & & N.D. & & N.D. \\
\hline 3 & & 1102 & & 738 & & N.D. & & N.D. \\
\hline 4 & & 615 & & 230 & & N.D. & & N.D. \\
\hline 10 & & 485 & & 145 & & N.D. & & N.D. \\
\hline 11 & & 286 & & 46 & & N.D. & & N.D. \\
\hline 12 & & 437 & & 185 & & 3.4 & & 4.2 \\
\hline 13 & & 43 & & 12 & & N.D. & & N.D. \\
\hline 14 & & 38 & & 7.5 & & N.D. & & N.D. \\
\hline 15 & & 85 & & 23 & & N.D. & & N.D. \\
\hline
\end{tabular}




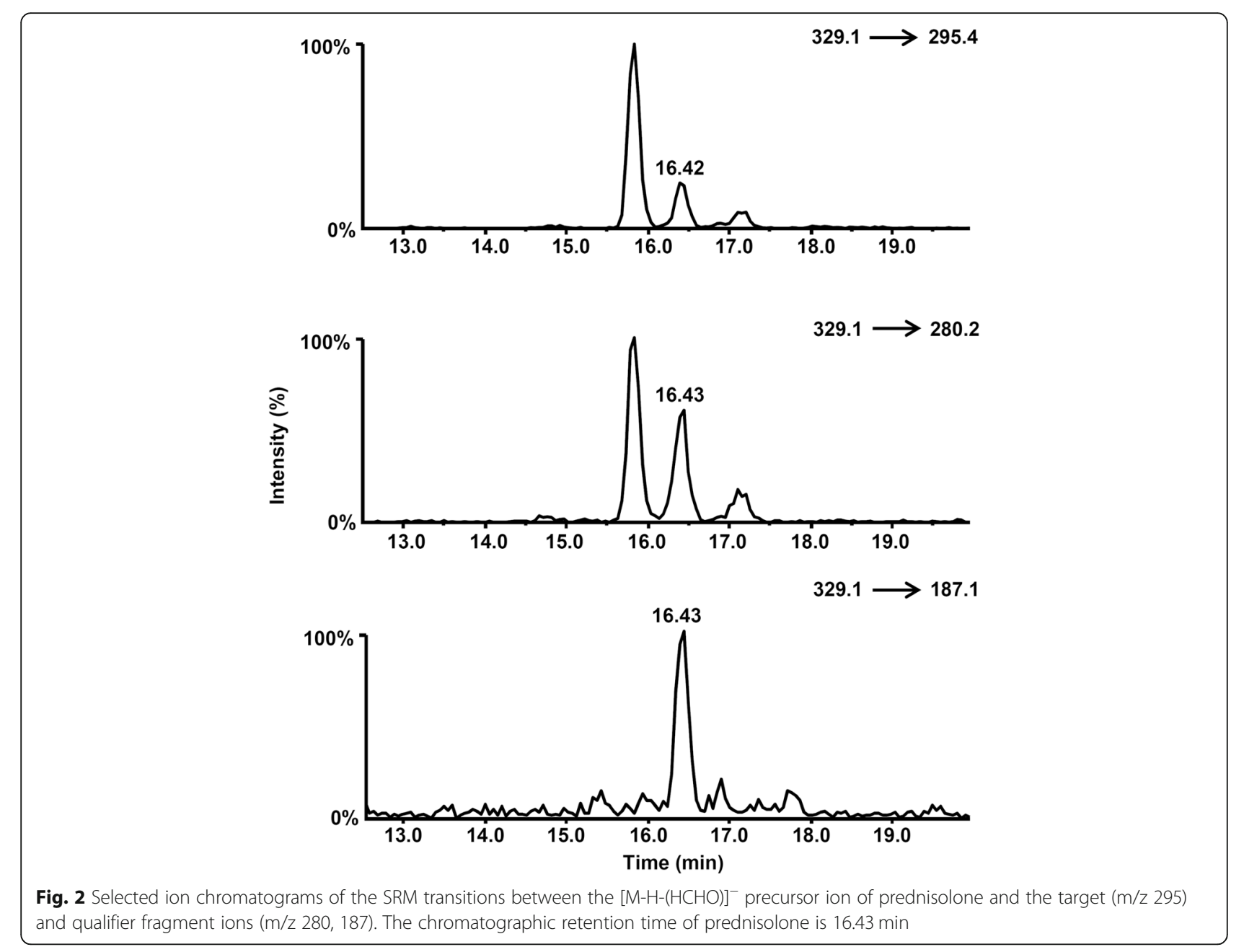

$4.2 \mu \mathrm{g} \mathrm{Kg}^{-1}$ respectively), but the corresponding urines proved negative for both compounds.

\section{Discussion}

The data from this study further confirm that, under conventional breeding conditions, no prednisolone or very limited amounts of it can be synthesized in cows and excreted in urine. Interestingly, no traces of prednisolone/prednisone nor their examined metabolites were found in the urines collected from cows sampled at farm and also negligible levels of cortisol and cortisone were recorded. In agreement with the results of previous studies $[4,9,11]$, our findings confirm that stressful events such as truck transportation followed by slaughtering increase the urinary levels of cortisol and cortisone up to several times as compared to those collected at farm. In our study, such a dramatic increase of cortisone and cortisol levels was associated with the production of prednisolone in only two animals out of fifteen, notably those whose urine contained the highest concentrations of cortisol (145 and $98 \mu \mathrm{g} \mathrm{L}^{-1}$ ). Remarkably, the prednisolone concentration measured in these two cases
( 0.57 and $0.60 \mu \mathrm{g} \mathrm{L}^{-1}$ ) was about one order of magnitude below the official threshold of $5.0 \mu \mathrm{g} \mathrm{L}^{-1}$ set by the Italian Ministry of Health. In both "positive" urine samples, the cortisol/prednisolone ratio appeared to be reversed with respect to that displayed by animals submitted to exogenous prednisolone administration for either therapeutic or growth-promoting purposes, when the presence of prednisolone and its metabolites was combined with low cortisol levels [8].

An important result of the present study is that neither the urine samples collected at farm nor those taken from slaughtered animals were found to contain measurable amounts of $20 \beta$-dihydroprednisolone, namely the most abundant urinary metabolite of prednisolone. Our results are corroborated by a previous investigation [11] in which neither $20 \alpha$ - nor 20 3 -dihydroprednisolone were detected in urines collected in "naturally stressed" bovines, namely 64 cows and 34 bulls after slaughtering. Likewise, Leporati et al. [12] reported that no 20ß-dihydroprednisolone nor any other prednisolone metabolites were found, even at trace levels, in the urine samples from 108 allegedly stressed cows involved in the "Bataille 
des Reines", a traditional bloodless tournament in which animals are allowed to fight spontaneously to assess dominance. In contrast, the cited study by De Clercq and coworkers [11] reported the detection of prednisolone, along with its $20 \alpha$ - and $20 \beta$-dihydroderivatives, in the urine of "artificially stressed" cows, subjected to i.m. treatment with tetracosactide, a synthetic ACTH analogue. Although the urine of the cows undergoing such a pharmacological treatment exhibited the occurrence of natural corticoids levels similar to those found in slaughtered cows, no plausible explanation was provided to justify the apparent discrepancy between absence and presence of prednisolone in naturally and artificially stressed animals, respectively. More recently, van Meulebroek et al. [10] reported the detection of $20 \beta$-dihydroprednisolone in all urine specimens collected from cows subjected to prednisolone treatment, under either therapeutic or (oral) growthpromoting schedule, as well as in cows treated (by i.m. injection) with tetracosactide to induce a pharmacological stress. In the latter paper, however, the relative increase in urinary cortisol and cortisone concentrations with respect to T0 values (i.e., prior to tetracosactide administration) was uniquely reported, so that a direct comparison with the absolute levels of natural corticoids recorded in naturally stressed cows [11] is not feasible. Based on the evidences presently available, the reasons for the seemingly different urinary pattern profile of prednisolone metabolites between naturally and artificially stressed cows remain to be elucidated. As a matter of fact, besides the cases of pharmacologically-induced stress, the presence of 20ß-dihydroprednisolone and other prednisolone metabolites in the cattle urine has been so far consistently associated only with the exogenous administration of the parent drug, either following a growth-promoting protocol or a therapeutic schedule $[8,10,13]$.

Earlier investigations disclosed that in-vitro cortisol incubation with bacteria [11] and bovine hepatic S9 preparations [3] resulted in the progressive decrease of cortisol along with the generation of prednisolone. This finding suggests that the liver is possibly the involved organ for the endogenous prednisolone synthesis. In the present study, neither prednisolone nor its dihydroderivatives could be detected in any liver sample of the slaughtered cows, including the two of them displaying the presence of urinary prednisolone. In addition, traces of cortisol corresponding to about $1 \mu \mathrm{g} \mathrm{Kg}^{-1}$ were detected in only one liver sample. This important evidence apparently indicate that transport and slaughtering stressing conditions are not associated with any significant increase of hepatic cortisol concentration, partly contradicting what was observed in the in-vitro investigations using much higher cortisol concentrations $(5 \mathrm{mM})$.
In a study characterized by an experimental design similar to the present one [9], measurable amounts of prednisolone were detected in about one third of the analysed adrenal glands along with high levels of cortisol. In our study, only one sample was found to contain prednisolone $\left(3.4 \mu \mathrm{g} \mathrm{Kg}^{-1}\right)$ along with relatively high concentrations of cortisol $\left(185 \mu \mathrm{g} \mathrm{Kg}^{-1}\right)$ and cortisone $\left(437 \mu \mathrm{g} \mathrm{Kg}^{-1}\right)$, but further five samples with similar or even much higher concentration of both natural corticoids did not show the presence of prednisolone at any level. In agreement with the observations of Bertocchi et al. [9], no correlation was found between the presence of prednisolone in the adrenal glands and in urine, suggesting that the endogenous synthesis of prednisolone is a complex phenomenon possibly involving different organs and tissues other than liver and adrenal glands.

\section{Conclusions}

This study confirms the sporadic presence of prednisolone traces (2 out 15) and the consistently increased concentration of cortisone and cortisol in the urines collected from cows subjected to truck transportation and subsequent slaughtering. The detected prednisolone levels were found much below the official cut off of $5.0 \mu \mathrm{g} \mathrm{L}^{-1}$ established to avoid false non-compliances. Based on the results of this and other studies [11, 14], it may also be concluded that, in cows subjected to various natural sources of stress, the occasional positive finding of urinary endogenous prednisolone is never matched by the presence of $20 \beta$-dihydroprednisolone or any other prednisolone metabolite. It is also evident that this irregular endogenous prednisolone biosynthesis cannot be directly attributed to a specific organ (liver or adrenal glands) and further research is needed to ascertain the possible sites of endogenous prednisolone synthesis in naturally stressed cows.

An evident limitation of the present study is the lack of standardization for the cattle transportation conditions to the abattoir, that introduces a potentially uncontrolled influencing factor possibly enhancing the correlated stress variability. While this limitation was inherently associated with the study commitment to investigate only cows at the end of their (re) productive cycle, making slaughtering by no means compelled by the scientific purpose to obtain more homogeneous experimental conditions, it is apparent that future development of the present study should more accurately model the stressing factors associated to cattle transport, including truck type, duration, distance, road conditions, and temperature and humidity environment.

\section{Methods}

\section{Urine, liver and adrenal gland collection}

Fifteen clinically healthy Piedmontese or Friesian cows (age range 8-14 years, average weight around $600 \mathrm{~kg}$ ) were enrolled in the study, which was conducted 
between mid- April and May. The monthly temperature in Piedmont, averaged for location, day and hour was $9.5^{\circ} \mathrm{C}$ in April and $12.8^{\circ} \mathrm{C}$ in May [15]. All cows were at the end of their (re) productive cycle and ready for slaughter. They were bred in two conventional farms (40-200 animals, respectively) located in the Turin and Cuneo provinces of Piedmont (northern Italy) and kept in tie stall barns. Farms were selected according to personal records and breeder formal declaration that the cows had not been subjected to any drug treatment in the last 30 days prior to sampling procedures, at least. Urine samples were first collected at farms under conditions of natural micturition, taking care to prevent faecal contamination. After 2 to 3 days, the animals were transported [16] to the abattoir (40 and $80 \mathrm{~km}$ journey from the two farms to the abattoir, on plain roads using single level trucks, with no facilities for measuring temperature and humidity). Transport was carried out according to Council Regulation (EC) N. 1/2005 and cows were slaughtered 30 to $45 \mathrm{~min}$ after the arrival. The animals were first desensitized with a captive-bolt pistol and then exsanguinated in the conventional way. Post-mortem sampling of liver and adrenal glands was performed by licensed veterinarians within $15 \mathrm{~min}$ from slaughtering, together with urine from the urinary bladder. After collection, all samples were immediately refrigerated (put on ice), frozen at $-20^{\circ} \mathrm{C}$ within $4 \mathrm{~h}$, and subsequently conferred to the analytical laboratory. The whole study was conducted under the strict control of the Regional Veterinary Public Services of Torino and Cuneo (Piedmont, Italy).

\section{Chemicals, reagents, and standard solutions}

Diethylether and acetonitrile together with cortisone, cortisol, prednisone, and prednisolone analytical standards were supplied by Sigma-Aldrich (St. Louis, MO, USA). All solvents were of analytical grade. $20 \alpha$-dihydroprednisolone, $20 \beta$-dihydroprednisolone, 6 $\beta$-hydroxyprednisolone, and $20 \beta$-dihydroprednisone were supplied by Steraloids (Newport, RI, USA). Cortisol D2, cortisone D2, and prednisolone D6 were purchased from $\mathrm{C} / \mathrm{D} / \mathrm{N}$ Isotopes Inc. (Pointe-Claire, Quebec, Canada). Triamcinolone acetonide D6 was from RIVM (Bilthoven, The Nederlands). Sodium hydroxide and hydrochloric acid were supplied by Carlo Erba Reagenti (Milan, Italy). Betaglucuronidase/ aryl-sulfatase was from Roche Diagnostics (Mannheim, Germany). Ultrapure water was obtained by a Milli-Q Millipore system (Bedford, MA, U.S.A.).

Stock standard solutions of the analytes were prepared in acetonitrile at a concentration of $1 \mathrm{mg} \mathrm{L}^{-1}$ and stored at $-20^{\circ} \mathrm{C}$ in the dark. Working acetonitrile solutions containing all the analytes at different concentrations were prepared by proper dilution. The working solutions were used to spike negative urine samples for the validation of the analytical method.

\section{Sample preparation Urine}

Sample preparation was conducted as reported elsewhere (Vincenti et al. 2012). Briefly, $5 \mathrm{~mL}$ urine samples were subjected to a liquid/liquid extraction at $\mathrm{pH}=8.5-$ 9.5 with diethylether, after $\beta$-glucuronidase/arylsulfatase deconjugation. After centrifugation, the supernatant organic phase was transferred into a $10 \mathrm{~mL}$ glass tube and evaporated to dryness under nitrogen with $40^{\circ} \mathrm{C}$ heating. The residue was dissolved in $50 \mu \mathrm{L}$ of a water:acetonitrile mixture $(70: 30 \mathrm{v} / \mathrm{v})$ solution and transferred into the analytical vials for the analysis.

\section{Liver/adrenal gland}

Sample aliquots of $2.5 \mathrm{~g}$ were homogenized in $5 \mathrm{ml}$ acetate buffer and then added with $50 \mu \mathrm{L}$ of the internal standard mix solution at $0.1 \mathrm{ng} \mathrm{L}^{-1}$. Further acetate buffer $0.1 \mathrm{M}$ was added $(5 \mathrm{~mL} ; \mathrm{pH}=5)$ and the extraction was carried out by $5 \mathrm{~min}$ shaking plus $5 \mathrm{~min}$ ultrasonic bath. After centrifugation (3500 rpm for $5 \mathrm{~min}$ ), the aqueous phase was extracted with $10 \mathrm{~mL}$ of tert-butyl methyl ether. The organic phase was transferred into a $10 \mathrm{~mL}$ glass tube and evaporated to dryness under a gentle stream of nitrogen and mild heating $\left(50^{\circ} \mathrm{C}\right)$. For adrenal glands, a further washing step was executed to remove fat. The residue, dissolved in $2 \mathrm{~mL}$ acetonitrile, was washed with $2 \mathrm{~mL}$ of hexane and dried again. The residue was dissolved again in $50 \mu \mathrm{L}$ of a water:acetonitrile mixture $(70: 30 \mathrm{v} / \mathrm{v})$ solution and transferred into the analytical vial.

\section{Instrumental analysis}

All the samples were analysed by LC-MS/MS using the method previously described by Cannizzo et al. [17], and further implemented by Vincenti et al. [7] and Leporati et al. [13]. An Agilent 1100 LC was interfaced to an Applied Biosystems API 4000 triple quadrupole mass spectrometer (Applied Biosystems Sciex, Ontario, Canada), operating in atmospheric pressure chemical ionization (APCI). Each sample was analysed twice and quantified by means of a calibration curve, using internal standard correction.

For the urine and adrenal gland samples that were found positive to prednisolone at concentrations lower than the $\mathrm{CC} \alpha$ (i.e., matching the prednisolone reference standard in terms of retention time and presence and relative abundance of the product ions), the correct identification of prednisolone was further confirmed by reprocessing the samples under a different MS/MS acquisition method. Following the procedure described by Savu and coworkers [18], the APCI source was operated 
Table 3 Instrumental parameters for prednisone and prednisolone using the confirmation method based on negative APCI and "in source" collisional fragmentation of the deprotonated molecular ion to yield the $[\mathrm{M}-\mathrm{H}-(\mathrm{HCHO})]^{-}$precursor ion

\begin{tabular}{|c|c|c|c|c|c|c|c|c|c|c|}
\hline \multirow[t]{3}{*}{ MS parameters } & \multicolumn{6}{|c|}{ CUR $=20$ psi } & \multicolumn{4}{|c|}{$C A D=2 p s i$} \\
\hline & \multicolumn{6}{|c|}{ GS1 = 50 psi } & \multicolumn{4}{|c|}{$\mathrm{T}=300^{\circ} \mathrm{C}$} \\
\hline & \multicolumn{6}{|c|}{$N C=-3 V$} & \multicolumn{4}{|c|}{ ihe $=\mathrm{ON}$} \\
\hline \multicolumn{3}{|l|}{ SRM protocol } & \multicolumn{2}{|c|}{ Target } & \multicolumn{3}{|c|}{ Qualifier 1} & \multicolumn{3}{|c|}{ Qualifier 2} \\
\hline Analyte & Precursor lon & $\mathrm{DP}(\mathrm{V})$ & Fragment & CE $(V)$ & Fragment & (qualifier 1/quantifier \%) & CE $(V)$ & Fragment & (qualifier 2/quantifier \%) & $C E(V)$ \\
\hline Prednisolone & 329.1 & -96 & 295.4 & -25 & 280.2 & $90 \%$ & -31 & 187.1 & $81 \%$ & -25 \\
\hline Prednisone & 327.2 & -90 & 149.2 & -39 & 285.4 & $45 \%$ & -25 & 270.3 & $26 \%$ & -28 \\
\hline
\end{tabular}

CUR curtain gas, GS1 nebulizer gas, NC nebulizer current, CAD collision gas, $T$ temperature, ihe interface heater, $D P$ declustering potential, $C E$ collision energy

in the negative ion mode under high declustering potential (DP), which induced an "in-source" fragmentation of the deprotonated molecular ion $(\mathrm{M}-\mathrm{H})^{-}$yielding a loss of formaldehyde $(\mathrm{HCHO} ; 30 \mathrm{Da})$ from the $\left(\mathrm{C}_{21}\right)$ hydroxymethyl group and the formation of the $[\mathrm{M}-\mathrm{H}-$ $(\mathrm{HCHO})]^{-}$precursor ion with considerable abundance. The latter was subsequently fragmented under selected reaction monitoring (SRM) conditions. The experimental settings are reported in Table 3.

\section{Method validation}

For urine and liver samples, the method was validated accordingly to 2002/657/CE Decision (2002/657 CE Decision) for prednisone and prednisolone [17]. For other analytes a simplified validation protocol was applied $[7,13]$.

For the screening analysis of the adrenal glands a new and simplified validation protocol was executed. This matrix is not adopted for the official controls of the Italian National Residue Plan [19]. SRM transitions with corresponding potentials for target compounds and internal standards are reported in Table 4.
Since cortisol is synthesized from cholesterol in the zona fasciculata of the adrenal cortex, no blank matrix for cortisol and cortisone is available, forcing us to build the calibration curves from standard solutions.

The assessment of specificity, linearity, precision, accuracy was included in the validation procedure.

\section{Specificity}

Ten adrenal glands were extracted and analysed as described above. The occurrence of possible interferences from endogenous substances was tested by monitoring the SRM profiles characteristic for each investigated compound, at the retention time interval expected for their elution.

\section{Linearity}

The instrumental linearity was studied to estimate if the quantification range of the method is encompassed by the instrumental dynamic linear range. Five concentrations of each analyte pure standard solutions $(0,25,50$, $100,250,500 \mu \mathrm{g} \mathrm{L}^{-1}$ for prednisone and prednisolone, 0 ,

Table 4 Instrumental conditions used for validating the analytical method and subsequently used in the screening of adrenal gland

\begin{tabular}{|c|c|c|c|c|c|c|c|c|}
\hline \multirow{2}{*}{$\begin{array}{l}\text { Analyte (correspondent IS in } \\
\text { brackets) }\end{array}$} & \multirow[t]{2}{*}{$t_{R}(\min )$} & \multirow[t]{2}{*}{ Precursor lon } & \multirow[t]{2}{*}{$\mathrm{DP}(\mathrm{V})$} & \multicolumn{2}{|c|}{ Target } & \multicolumn{3}{|c|}{ Qualifier } \\
\hline & & & & Fragment & $C E(V)$ & Fragment & (qualifier/quantifier \%) & CE $(V)$ \\
\hline 6ß-hydroxyprednisolone (A) & 4.78 & 377.1 & 47 & 341.1 & 11 & 323.2 & $28 \%$ & 15 \\
\hline 20a-dihydroprednisolone (A) & 11.28 & 363.3 & 37 & 345.2 & 15 & 309.3 & $75 \%$ & 18 \\
\hline 20ß-dihydroprednisolone (A) & 12.58 & 363.3 & 37 & 345.2 & 15 & 309.3 & $24 \%$ & 18 \\
\hline 20ß-dihydroprednisone (A) & 12.87 & 361.3 & 55 & 153.0 & 21 & 313.2 & $54 \%$ & 16 \\
\hline Prednisolone (A) & 17.16 & 361.3 & 55 & 343.3 & 16 & 325.3 & $38 \%$ & 16 \\
\hline Prednisone (A) & 17.68 & 359.1 & 70 & 341.1 & 17 & 313.2 & $41 \%$ & 19 \\
\hline Cortisol (B) & 17.72 & 363.2 & 69 & 121.3 & 33 & 147.3 & $67 \%$ & 44 \\
\hline Cortisone (C) & 18.64 & 361.2 & 83 & 163.4 & 36 & 105.3 & $14 \%$ & 64 \\
\hline \multicolumn{9}{|l|}{ Internal standards } \\
\hline Prednisolone D6 & 16.95 & 367.1 & 48 & 330.3 & 16 & - & - & - \\
\hline Cortisol D2 & 17.68 & 365.2 & 65 & 121.8 & 39 & - & - & - \\
\hline Cortisone D2 & 18.61 & 363.1 & 67 & 165.1 & 34 & - & - & - \\
\hline
\end{tabular}

DP Declustering Potential, CE Collision Energy 
$100,250,500,750,1000 \mu^{-1} \mathrm{~L}^{-1}$ for prednisolone and prednisone metabolites, and $0,0.5,1.25,2.5,5,12.5 \mathrm{mg} \mathrm{L}^{-1}$ for cortisol and cortisone) were injected, to set up the linearity testing curves. Each level was injected in triplicate.

\section{Precision and trueness}

Intraday precision (expressed as percent variation coefficient, $\mathrm{CV} \%$ ) and trueness (expressed as bias\%) were evaluated at three concentration levels: $0.5,2$ and $10 \mu \mathrm{g}$ $\mathrm{Kg}^{-1}$ for prednisone and prednisolone, 2, 10 and $20 \mu \mathrm{g}$ $\mathrm{Kg}^{-1}$ for prednisone and prednisolone metabolites. Five replicates of adrenal gland samples were spiked with the standard solutions at three concentration levels. Intraday precision was considered satisfactory when $\mathrm{CV} \%$ values were below $15 \%$. Satisfactory trueness was achieved when the experimentally determined average concentration lied within $\pm 15 \%$ from the expected value.

\section{Abbreviations}

ACTH: Adrenocorticotropic hormone; APCl: Atmospheric pressure chemical ionization; CCa: Decision limit; CE: Collision energy; DP: Declustering potential; LC: Liquid chromatography; MS/MS: Tandem mass spectrometry; R2: Determination coefficient; SRM: Selected reaction monitoring

\section{Acknowledgements}

Not applicable.

\section{Authors' contributions}

All Authors participated to the study design and planning. GB, CN and MV organized the project and agreed the objectives of the study. SG and AA selected farms and animals, then organized and executed the sample collection. PC and ML performed the analytical method validation, sample treatment and instrumental analysis. PC and ML wrote the initial draft of the manuscript. $\mathrm{CN}$ and MV made the critical revision and refinement of the manuscript. GB guaranteed the project's funding. All Authors read and approved the final manuscript.

\section{Funding}

Financial support for this study was obtained from the grant entitled "Determinazione di prednisolone e suoi metaboliti in bovini da latte e da carne; biotrasformazioni endogene in condizioni sperimentali di campo e di laboratorio" provided by the local government: Regione Piemonte Direzione Sanità - Prevenzione Veterinaria. The Piedmont regional government endorses researches addressed to fight the illegal administration of drugs to farm animals and promotes safe food policies by supporting programs of applied research. The funding body was represented by one of the Authors (G.B.), who has lifelong specific competence in the present research field and participated to the study design, data interpretation meeting, and final manuscript approval. In particular, the funding body patronized the study and collaborated to the farmers' recruitment and the involvement of the public veterinary services into the project.

\section{Availability of data and materials}

Raw data for calculation of method validation, tables, and figures are available from the corresponding author upon request.

\section{Ethics approval and consent to participate}

According to what established by the Italian law D.Lgs. 26/2014 [20] transposing the Directive 2010/63/EU on animal experimentation, all the measures intended for the protection of animals used for scientific or educational purposes do not apply to non-experimental veterinary clinical practices (e.g. urine sampling, truck transportation for slaughtering, slaughtering). It should be also noted that i) all the cows enrolled in the study were at the end of their productive cycles and ii) the date of truck transportation to the abattoir was agreed with the farmers upon their requests. Based on what outlined above, no formal approval by the Health Ministry or the Bioethical Committee were required. The Direction of the veterinary services of the regional Government (Regione Piemonte, Direction of Public Health) supported and supervised the whole study. Oral consent to participation was explicitly expressed by the farm owners, who provided dedicated collaboration to the sampling procedures.

\section{Consent for publication}

Not applicable.

\section{Competing interests}

The authors declare that they have no competing interests.

\section{Author details}

${ }^{1}$ Istituto Zooprofilattico Sperimentale del Piemonte, Liguria e Valle d'Aosta, Torino, Italy. ${ }^{2}$ Centro Regionale Antidoping e di Tossicologia "A. Bertinaria", Orbassano (Torino), Italy. ${ }^{3}$ Dipartimento di Scienze Veterinarie, Università degli Studi di Torino, Grugliasco (Torino), Italy. ${ }^{4}$ Azienda Sanitaria Locale di Collegno e Pinerolo - ASL TO3, Collegno (Torino), Italy. ${ }^{5}$ Azienda Sanitaria Locale di Cuneo, Mondovì - ASL CN1, Cuneo, Italy. ${ }^{6}$ Regione Piemonte Direzione Sanità Pubblica, Torino, Italy. ${ }^{7}$ Dipartimento di Chimica, Università degli Studi di Torino, Via Pietro Giuria, 7, 10125 Torino, Italy.

Received: 5 September 2018 Accepted: 30 August 2019

Published online: 18 September 2019

References

1. Courtheyn D, Le Bizec B, Brambilla G, De Brabander HF, Cobbaert E, Van de Wiele M, Vercammen J, De Wasch K. Recent developments in the use and abuse of growth promoters. Anal Chim Acta. 2002;473:71-82.

2. McDonald M, Granelli K, Sjöberg P. Rapid multiresidue method for the quantitative determination and confirmation of glucocorticosteroids in bovine milk using liquid chromatography-electrospray ionization-tandem mass spectrometry. Anal Chim Acta. 2007;588:20-5

3. de Rijke E, Zoontjes PW, Samson D, Oostra S, Sterk SS, van Ginkel LA. Investigation of the presence of prednisolone in bovine urine. Food Addit Contam Part A-Chem. 2014:31:605-13.

4. Pompa G, Arioli F, Casati A, Fidani M, Bertocchi L, Dusi G. Investigation of the origin of prednisolone in cow urine. Steroids. 2011;76:104-10.

5. Ferranti C, Quadri FD, Palleschi L, Marchiafava C, Pezzolato M, Bozzetta E, Caramelli M, Draisci R. Studies on the presence of natural and synthetic corticosteroids in bovine urine. Steroids. 2011;76:616-25.

6. Memorandum from the Italian Ministry of Health - Department of Public and Veterinary Health - from the opinion of the Consiglio Superiore di Sanità. Seduta del 22 maggio: Sessione XL VIII, Sezione IV; 2012. www.salute. gov.it. Accessed 5 Sept 2019.

7. Vincenti M, Leporati M, Capra P, Gatto S, Attucci A, Barbarino G, Nebbia C. A field survey on the presence of prednisolone and prednisone in urine samples from untreated cows. Food Addit Contam Part A-Chem. 2012;29: 1893-900.

8. Nebbia C, Capra P, Leporati M, Girolami F, Barbarino G, Gatto S, Vincenti M. Profile of the urinary excretion of prednisolone and its metabolites in finishing bulls and cows treated with a therapeutic schedule. BMC Vet Res. 2014;10:237

9. Bertocchi L, Dusi G, Ghidelli V, Hathaway T, Nassuato C, Casati A, Fidani M, Pompa G, Arioli F. Investigation of the origin of prednisolone in urine and adrenal glands of cows. Food Addit Contam A-Chem. 2013;30:1055-62.

10. Van Meulebroek L, De Clercq N, Vanden Bussche J, Devreese M, Fichant E, Delahaut P, Croubels S, Vanhaecke L. Pharmacokinetic and urinary profiling reveals the prednisolone/cortisol ratio as a valid biomarker for prednisolone administration. BMC Vet Res. 2017:13:236.

11. De Clercq N, Van Meulebroek L, Bussche JV, Croubels S, Delahaut P, Vanhaecke $L$. The impact of stress on the prevalence of prednisolone in bovine urine: a metabolic fingerprinting approach. J Steroid Biochem Mol Biol. 2015;154:206-16.

12. Kristeva MA, Grigorova PM. Transformation of cortisol to prednisolone by viable cells of Arthrobacter simplex covalently immobilized on cellulose granules. Enzym Microb Technol. 1987:9:538-41.

13. Leporati M, Capra P, Cannizzo FT, Biolatti B, Nebbia C, Vincenti M. Determination of prednisolone metabolites in beef cattle. Food Addit Contam A-Chem. 2013;30:1044-54. 
14. Leporati M, Nobile M, Capra P, Alladio E, Vincenti M. Determination of endogenous and exogenous corticosteroids in bovine urine and effect of fighting stress during the "Batailles des Reines" on their biosynthesis. Res Vet Sci. 2017:114:423-9.

15. http://www.arpa.piemonte.it/rischinaturali/accesso-ai-dati/annali_ meteoidrologici/ annali-meteo-idro/banca-dati-meteorologica.html. Last access: July 22th, 2019.

16. Council Regulation (EC) N. 1/2005 of 22 December 2004 on the protection of animals during transport and related operations and amending Directives 64/432/EEC \& 93/119/EC and Regulation (EC) N. 1255/97. http:// data.europa.eu/eli/reg/2005/1/oj. Accessed 5 Sept 2019.

17. Cannizzo FT, Capra P, Divari S, Ciccotelli V, Biolatti B, Vincenti M. Effects of low-dose dexamethasone and prednisolone long term administration in beef calf: chemical and morphological investigation. Anal Chim Acta. 2011; 700:95-104.

18. Savu SR, Silvestro L, Haag A, Sorgel F. A confirmatory HPLC-MS/MS method for ten synthetic corticosteroids in bovine urines. J Mass Spectrom. 1996;31:1351-63.

19. Italian National Residue Plan 2018 - Ministry of Health. www.salute.gov.it. Accessed 5 Sept 2019.

20. Decreto Legislativo 4 marzo 2014 n. 26: Attuazione della direttiva 2010/63/ UE sulla protezione degli animali utilizzati a fini scientifici. 2014; GURI n.61, 14-3-2014). https://www.gazzettaufficiale.it/eli/id/2014/03/14/14G00036/sg. Accessed 5 Sept 2019

\section{Publisher's Note}

Springer Nature remains neutral with regard to jurisdictional claims in published maps and institutional affiliations.

Ready to submit your research? Choose BMC and benefit from:

- fast, convenient online submission

- thorough peer review by experienced researchers in your field

- rapid publication on acceptance

- support for research data, including large and complex data types

- gold Open Access which fosters wider collaboration and increased citations

- maximum visibility for your research: over $100 \mathrm{M}$ website views per year

At BMC, research is always in progress.

Learn more biomedcentral.com/submissions 